\title{
Analysis of percutaneous vertebroplasty-a prospective study
}

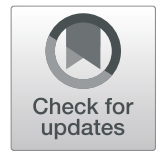

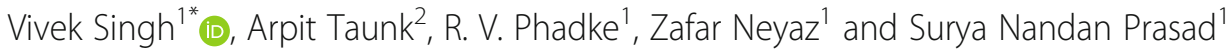

\begin{abstract}
Background: The objective of this study was to document the efficacy of vertebroplasty procedure for pain relief and also to measure pain-related disability and quality of life after the procedure, as well as to access whether the amount of cement injected affects the outcome.

Results: Fifty patients with severe pain not responding to conservative management of vertebral collapse were included in this study. Clinical severity of pain was documented in a 10-point ordinal scale. Mean preoperative pain score was $7.3 \pm 1.2$, and activity score was $1.6 \pm 1.1$. The analgesic score was $1.0 \pm 0.2$. Eight and 14 patients had clinical improvement in symptoms immediate and at 1 week, respectively, after the procedure. At 3-month followup, 16 patients (32\%) became asymptomatic, 30 patients (60\%) showed significant improvement, while 4 of them (8\%) had no improvement in symptoms. This suggests that there is a significant relief in clinical symptoms at 3month follow-up.

Conclusion: Vertebroplasty is a safe, cost-effective, sustainable minimal invasive procedure for the treatment of pain associated with vertebral fractures/collapse associated with different vertebral pathologies with high success rate. Accurate and correct selection of patients is mandatory for the success of the procedure.
\end{abstract}

Keywords: Vertebroplasty, Osteoporotic collapse, Vertebral hemangioma, Bone cement

\section{Background}

Osteoporosis and osteoporotic compression fracture are increasingly prevalent with aging population. Pain is the most common symptom for which medical assistance is sought in this set of population. Osteoporotic and nonosteoporotic vertebral deformities are equally responsible for musculoskeletal pain and other morbidities in an older age group. Clinical and subclinical vertebral fractures may cause persistent often excruciating pain, which impairs mobility and reduces the patient's quality of life [1]. The updated American College of Radiology (ACR) Criteria for vertebral compression fractures management emphasize on conservative approach; however, anti-osteoporotic medications, calcium, and vitamin D should be started immediately [2]. Pain relief is of utmost concern in these sets of patients which may require a short course of anti-inflammatory for 1-2 months. If unresponsive patients or a longer duration of pain killer requirement is there, then vertebroplasty or kyphoplasty

\footnotetext{
* Correspondence: singhvivek79@rediffmail.com

${ }^{1}$ Neuroradiology, SGPGIMS, Lucknow, India

Full list of author information is available at the end of the article
}

should be strongly considered. Percutaneous vertebroplasty was initially described by French radiologists for the treatment of painful vertebral hemangioma, metastatic lesions, and myeloma [2]. With time, it has evolved fluently and is now also being used in patients with osteoporotic compression fractures. The primary goal of treatment by vertebroplasty is to alleviate pain, and the other goal is vertebral body stabilization.

We conducted a study in our department where 50 prospective patients of vertebroplasty were studied to assess procedural efficacy in pain relief immediate and long-term sustainability and also to assess any correlation between the amount of bone cement injected and pain relief.

\section{Methods}

The study was done in Department of Radiodiagnosis, Sanjay Gandhi PostGraduate Institute of Medical Sciences, from 1 January 2014 to 31 October 2015. Fifty prospective patients were selected for study, and these patients were followed up until December 2017.

Patient selection: 
Inclusion criteria:

1. Patients having osteoporotic vertebral compression fractures in the cervical, thoracic, and lumbar spine causing moderate to severe pain and unresponsive to conservative therapy

2. Patients with painful metastasis and multiple myelomas with or without adjuvant radiation or surgical therapy

3. Patients with painful vertebral hemangiomas

\section{Clinical assessment}

A general physical, neurological, and systemic examination was performed before taking up patients for percutaneous vertebroplasty. Tenderness at the site of pain was evaluated. The clinical severity of pain was documented in a 10-point ordinal scale (VAS; visual analog scale) pre- and post-procedure and also on follow-up visits. Patients were asked to rate their pain according to the severity.

\section{Pain severity score}

The VAS pain scoring system was used for evaluation of severity of pain.

$$
\begin{aligned}
& 0=\text { No pain } \\
& 10=\text { Most severe pain }
\end{aligned}
$$

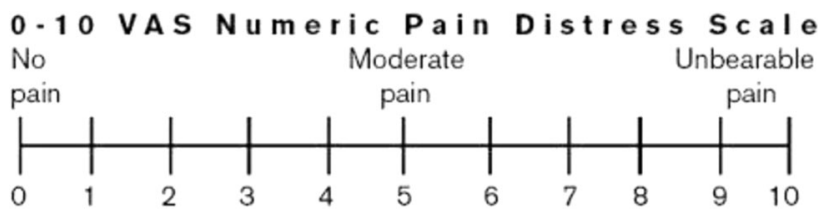

Activity score and intake of analgesics were documented in a 5-point score, respectively, before and after the procedure as well as on the follow-up.

\section{Activity score}

Independent without assistance
Walk with assistance
Bound to wheel chair
Sitting in bed
Lying in bed

\section{Medication score}

0 None

1 NSAIDs

2 Non-narcotic opioids

3 Narcotic drugs

4. IV narcotic drugs
The score ranged from a minimum of zero to a maximum of 18. The patients were examined, and all the systemic and neurological findings were noted.

\section{Pre-procedure investigations which were included in the study}

Laboratory investigations which were done for patients:

1. Complete blood count

2. Coagulation profile.

\section{Imaging}

All imaging including anterior and lateral radiographs of the spine and if patient had CT or MRI were also reviewed.

\section{Procedure}

We performed all procedures in an angiographic unit with a C-arm digital subtraction angiography (DSA) fluoroscopy system used in 50 patients. Patients were asked to stop there pain killers at a minimum of 3 days before the procedure, and injectable antibiotic inj ceftriaxone $2 \mathrm{gm}$ was given just before procedure.

Patients were kept in a prone position, and all procedures were performed under strict sterile conditions. All procedures were done under local anesthesia via transpedicular approach using a 13 gauge needle. Gentle tapping guided the needle through the pedicle into the anterior third of the involved vertebral body. Frontal and lateral images were recorded with the needle in correct position.

\section{Preparation of the cement mixture}

We prepared a mixture of polymethyl methacrylate (PMMA) mixed with barium in toothpaste-like consistency. The prepared PMMA was slowly injected into the vertebral body, and satisfactory infiltration of the vertebral body was confirmed radiographically. The amount of cement injected was variable depending on the vertebral level that had to be treated and the size of the lesion: larger for dorsal and lumbar bodies and smaller for cervical bodies. The cement introduction was always performed under fluoroscopic guidance with a slow and careful injection of high viscosity material. The filling of the vertebra was aimed to obtain as complete and homogenous as possible without causing intraspinal leakage of bone cement. In case the unipedicular approach did not give the desired or aimed result, the other pedicle was also used (bipedicular approach). Injection was stopped when substantial resistance was met or when the cement reached the posterior quarter of the vertebral body; injection was also stopped if cement leaked into extra osseous structures or veins. The needle was then removed, and all patients were observed in the 


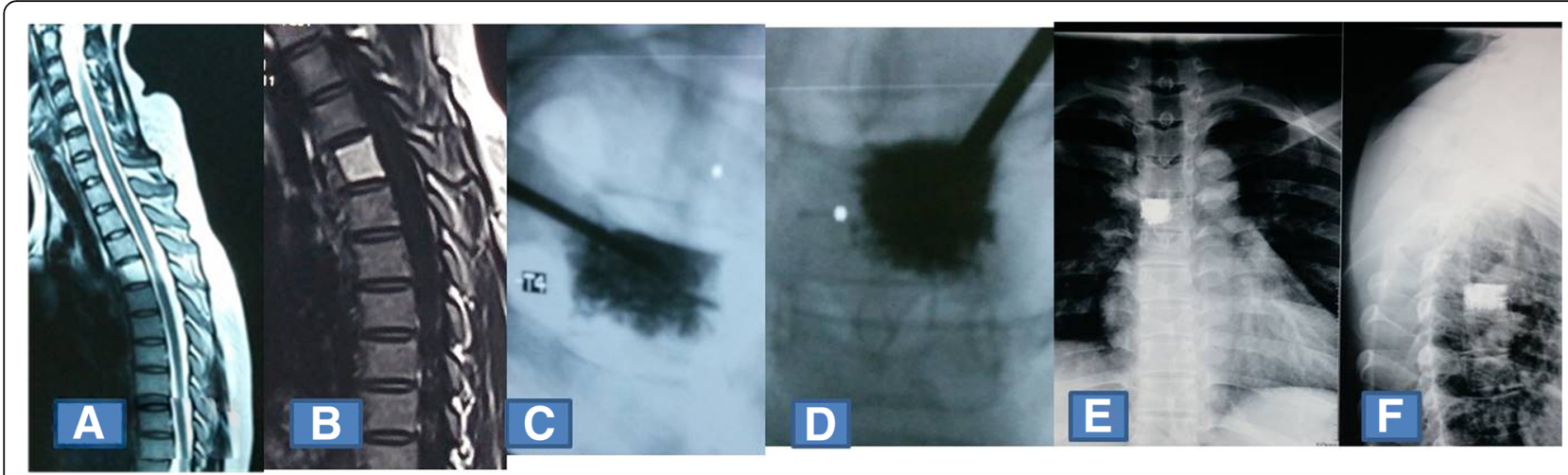

Fig. 1 A 25-year-old female with complaints of upper thoracic back pain with tenderness localized to T4. a, b MRI T1 and T2WI thoracolumbar spine shows a hyperintense lesion on both $\mathrm{T} 1$ and T2 s/o vertebral hemangioma in D4 vertebral body. $\mathbf{c}, \mathbf{d}$ DSA image AP and lateral view showing unipedicular injection of cement. e, $\mathbf{f}$ Post-vertebroplasty X-ray image of thoracic spine shows adequate filling of bone cement in the body of D4 vertebra with no extension in to IV disc space. On follow-up, patient had significant relief in pain with decrease in morbidity and no tenderness at D4 level

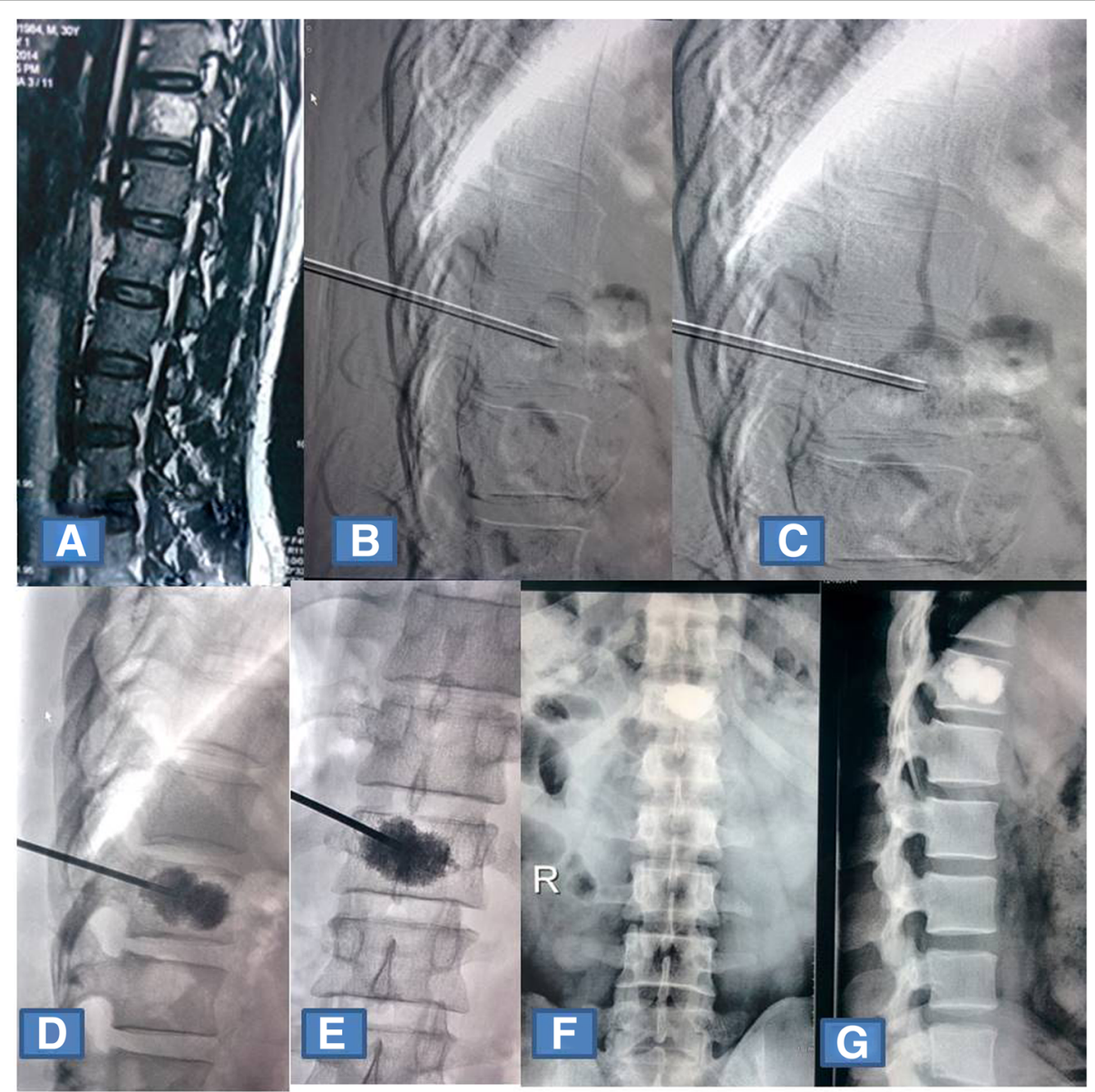

Fig. 2 A-30-year-old male patient presented with back pain since last 1 year seldom radiating to left lower leg. a MRI T2WI shows a vertebral hemangioma in D12 vertebral body. $\mathbf{b}$ DSA image lateral view showing transpedicular approach of needle placement at junction of anterior one third and posterior two third. c DSA image lateral view showing paravertebral venous plexus when contrast was injected so a thicker bone cement paste was used to prevent venous extension of cement. d, e DSA images showing adequate filling of vertebral body by cement. f, $\mathbf{g}$ Post-vertebroplasty X-ray image shows good filling of bone cement in the body of D12 vertebra. On follow-up, at 1 week, there was significant pain relief 
supine position for $2 \mathrm{~h}$ after the procedure. All participants in the vertebroplasty group received oral antibiotic for 3 days and analgesics if needed.

- Periprocedural complications were evaluated and were documented

- Postprocedural clinical evaluation was done to look for hemodynamic parameters and neurological status of the patient after the procedure

- Postprocedural imaging done by either frontal and lateral radiography or $\mathrm{CT}$ of the spine, and follow-up was done after 7 days and 3 months for assessing the severity of pain. Telephonic followup was done of all patients till December 2017 for analyzing pain.

Vertebroplasty procedure started with treatment for vertebral hemangiomas, and now is one of the main stay treatments for pain relief due to compressive pathologies to provide biomechanical strength.

The exact mechanism of pain relief following vertebroplasty is not known. Many theories have been proposed for mechanism of pain relief. The commonly considered theories include:

\section{- Mechanical theory}

Vertebroplasty leads to mechanical stabilization. The cement stabilizes fractures including microfractures within the cancellous bone of vertebral body and thus reduces the irritation of free nerve endings thereby reducing pain. This restores the strength and stiffness of the diseased vertebrae thus causing relief in pain [4].
- Thermal theory

The heat generated by PMMA cement leads to damage to the free nerve endings of vertebral nerves and thus reduces pain. Percutaneous vertebroplasty reduces pain by thermal neurolysis. As the bone cement begins to harden within the body, there occurs an exothermic process capable of producing temperatures as high as $70^{\circ} \mathrm{C}$, which in turn damage nerve endings sufficiently to negate pain [5].

- Decompression theory

The intraosseous pressure increases significantly following compression fracture in the vertebral body. This is decompressed after vertebroplasty, thus providing pain relief.

So, in brief, vertebroplasty offers analgesic effect, biomechanical strength, and antitumoral effect. The analgesic effect is due to in situ immobilization of fractures, destruction of nerve endings, cytotoxic effect, and exothermic reaction. The antitumoral effect is due to local toxicity of methyl-meth-acrylate $[6,7]$.

\section{Observation and results}

In our study, percutaneous vertebroplasty was done in 50 patients, out of which $37(74 \%)$ were female and 13 (26\%) were male.

The mean age was $52.65 \pm 13.1$ (range 20-69 years).

Out of the 50 patient's in our study, 11 patients $(22 \%)$ had vertebral hemangioma, 36 (72\%) had osteoporotic/ traumatic collapse and $3(6 \%)$ of them had vertebral collapse due to malignant etiology (multiple myeloma). Figures 1, 2, and 3 show symptomatic vertebral hemangioma where vertebroplasty is done.

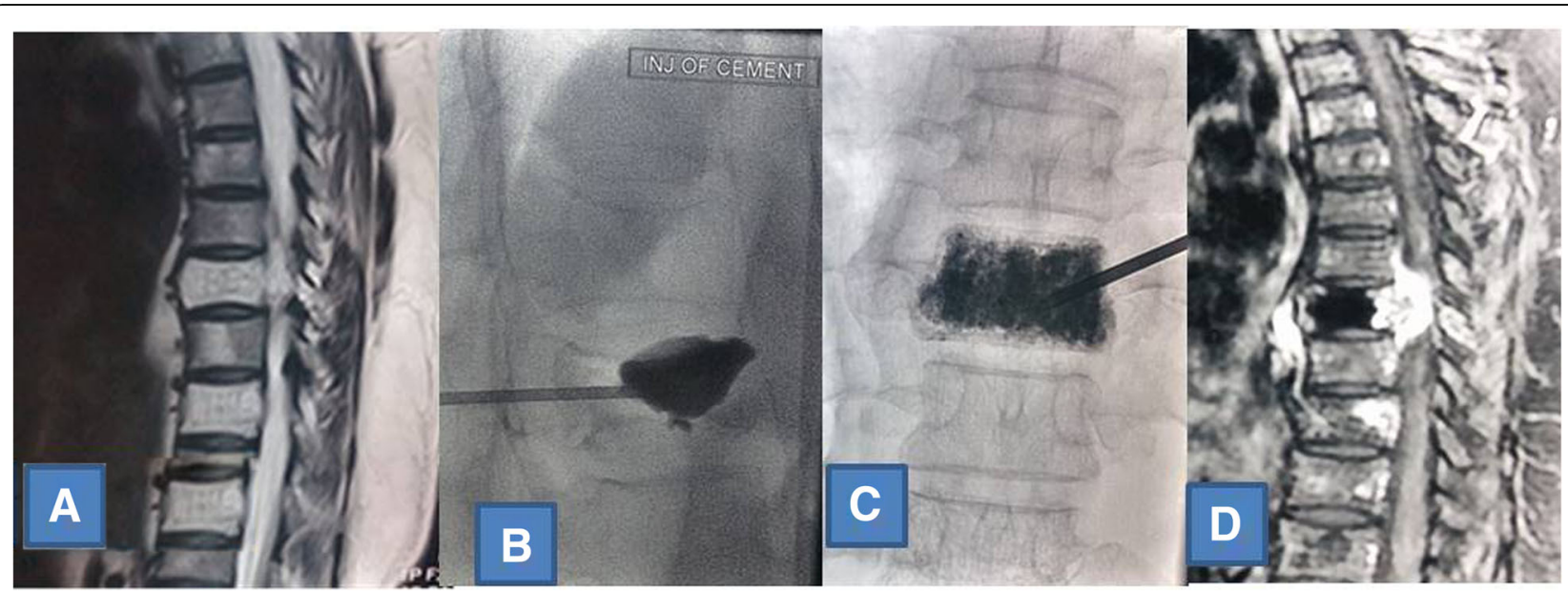

Fig. 3 A 55-year-old female with complaints of low back ache since last 6 months with signs and symptoms of compressive myelopathy since the last 4 months. a MRI T2WI shows a vertebral hemangioma in D9 and D11 vertebral body. b, c DSA image lateral and AP view showing transpedicular approach of unipedicular cement injection in to D9 vertebral body. d Post-vertebroplasty MRI T1 WI shows residual hemangioma in D9 vertebrae and an epidural component of aggressive hemangioma causing spinal canal stenosis leading to persistence of signs and symptoms post-vertebroplasty. This patient underwent surgical laminectomy to decrease spinal canal stenosis which relieved her symptoms 

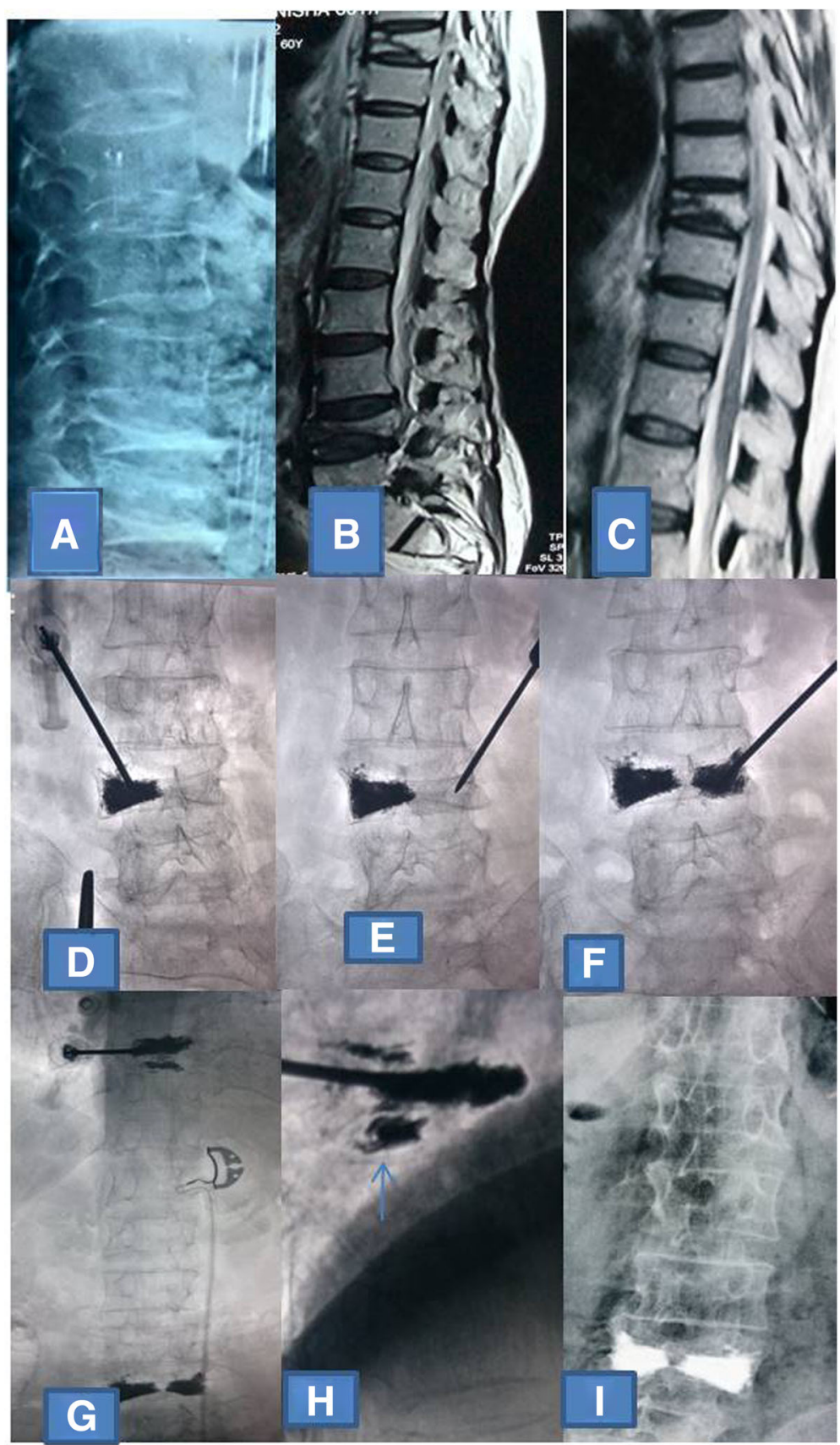

Fig. 4 A 50-year-old female with history of back ache pain since last one month. a X-ray lateral view lumbar vertebrae showing L4 osteoporotic collapse. b, c MRI T1 AND T2WI shows osteoporotic collapse of D9 and L4 vertebral body, with adjacent bone marrow edema. $\mathbf{d}$-f DSA images showing bipedicular approach of cement injection in L4 vertebrae. $\mathbf{g}$, $\mathbf{h}$ DSA images showing unipedicular cement injection in D9 vertebral body, magnified image of D9 vertebra showing extension of cement in adjacent intervertebral disc space(arrow). i Post-vertebroplasty X-ray image shows adequate filling of bone cement in the body of L4 vertebra. There was extension of cement mixture in to D9-D10 IV disc space. However, patient had no clinical symptoms of sensori-motor radiculopathy. Patient had significant relief in pain on 3-month follow-up

Figures 4, 5, and 6 show osteoporotic collapse, and Fig. 7 show post-traumatic collapse where vertebroplasty was done.

The diseased vertebrae were distributed between D4 and L5 vertebrae, in which the most common vertebrae was D12 in 11 patients (22\%) followed by L1 in 10 patients (20\%).

The most common symptom in study subjects was low back ache in 50 patients $(100 \%)$ followed by tenderness in 20 patients (40\%). 


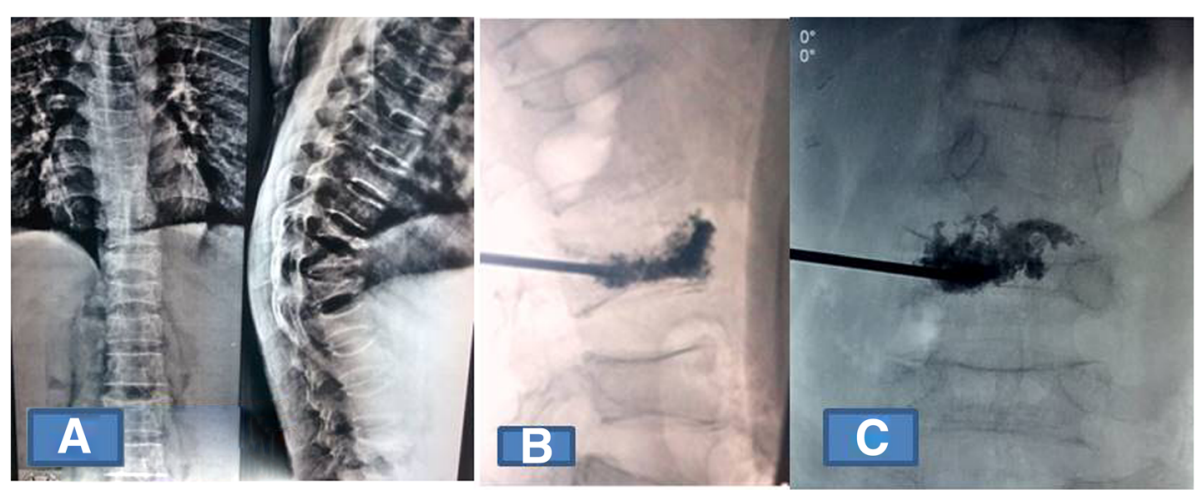

Fig. 5 A 29-year-old male who is suffering from thalassemia with history of regular interval repeated blood transfusions had lower lumbar back pain and inability to walk since last 6 months with tenderness at L4 vertebral level. a X-ray AP and lateral view of thoracolumbar spine showing multiple vertebral osteoporotic collapse with few vertebrae showing biconcave end plates. b DSA lateral view image showing unipedicular injection of cement in to collapse $L 4$ vertebrae. c DSA AP view showing adequate filling of $L 4$ vertebrae by cement mixture more on one half. The patient was a known case of thalassemia with history of multiple blood transfusions. Though there were multiple vertebral collapse, but patient had symptoms of pain and tenderness only at lumbar region. So, vertebroplasty was planned for L4 vertebrae. On follow-up, the patient had significant relief in pain and is now able to walk without support

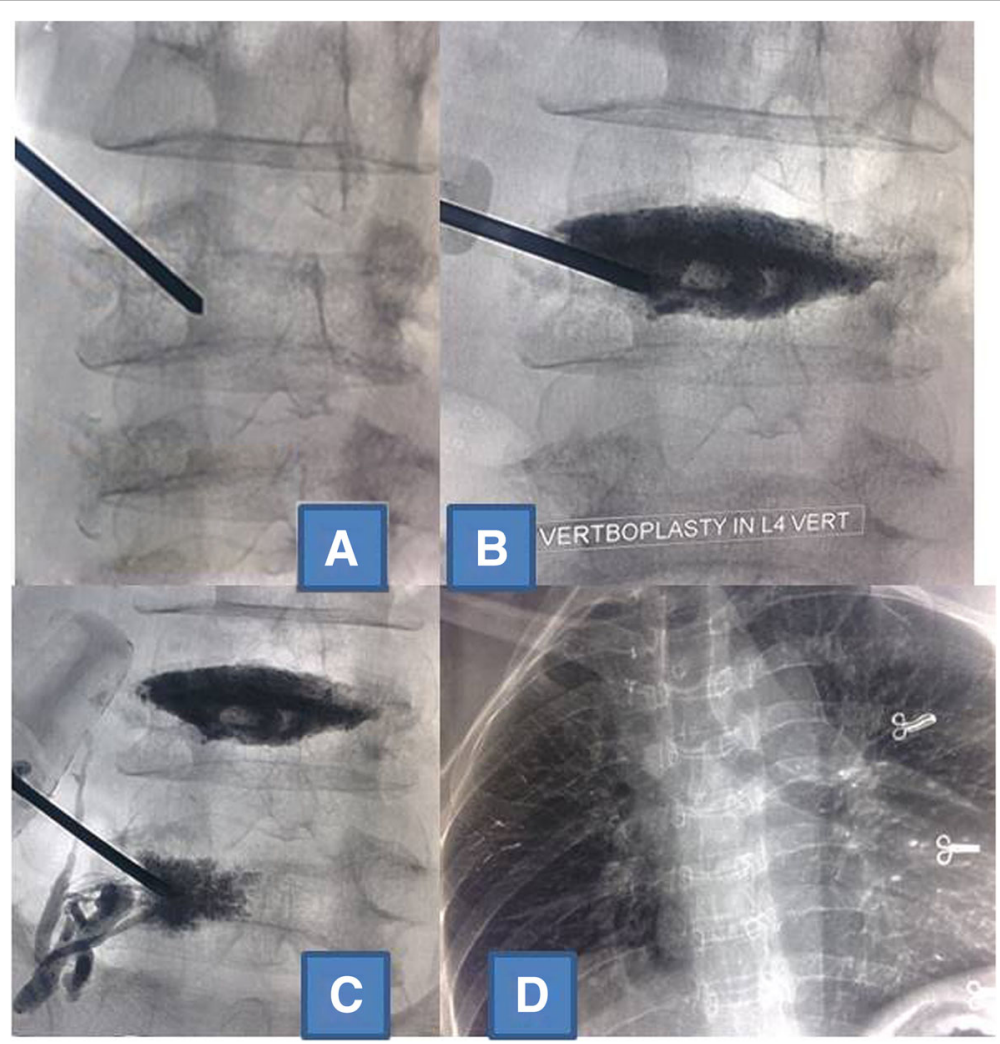

Fig. 6 A 59-year-old female with complaints of low back ache since the last 4 months. Her X-ray lumbar spine was done which shows osteoporotic collapse of L4 and L5 vertebrae. a DSA image showing transpedicular placement of needle in body of $L 4$ vertebrae in AP view. b DSA image showing adequate filling of cement in $L 4$ vertebral body in AP view. c DSA image $C$ showing needle in $L 5$ vertebral body with paravertebral venous extension of cement. $\mathbf{d}$ Thoracic fluoroscopy image showing linear streaks of barium in bilateral lung fields suggestive of pulmonary embolism of cement mixture. The patient had no clinical deterioration postprocedure. But the patient had intraprocedural complication of paravertebral venous extension of cement mixture extending into pulmonary embolism. So, she was closely followed up after the procedure had no clinical signs and symptoms of respiratory distress 


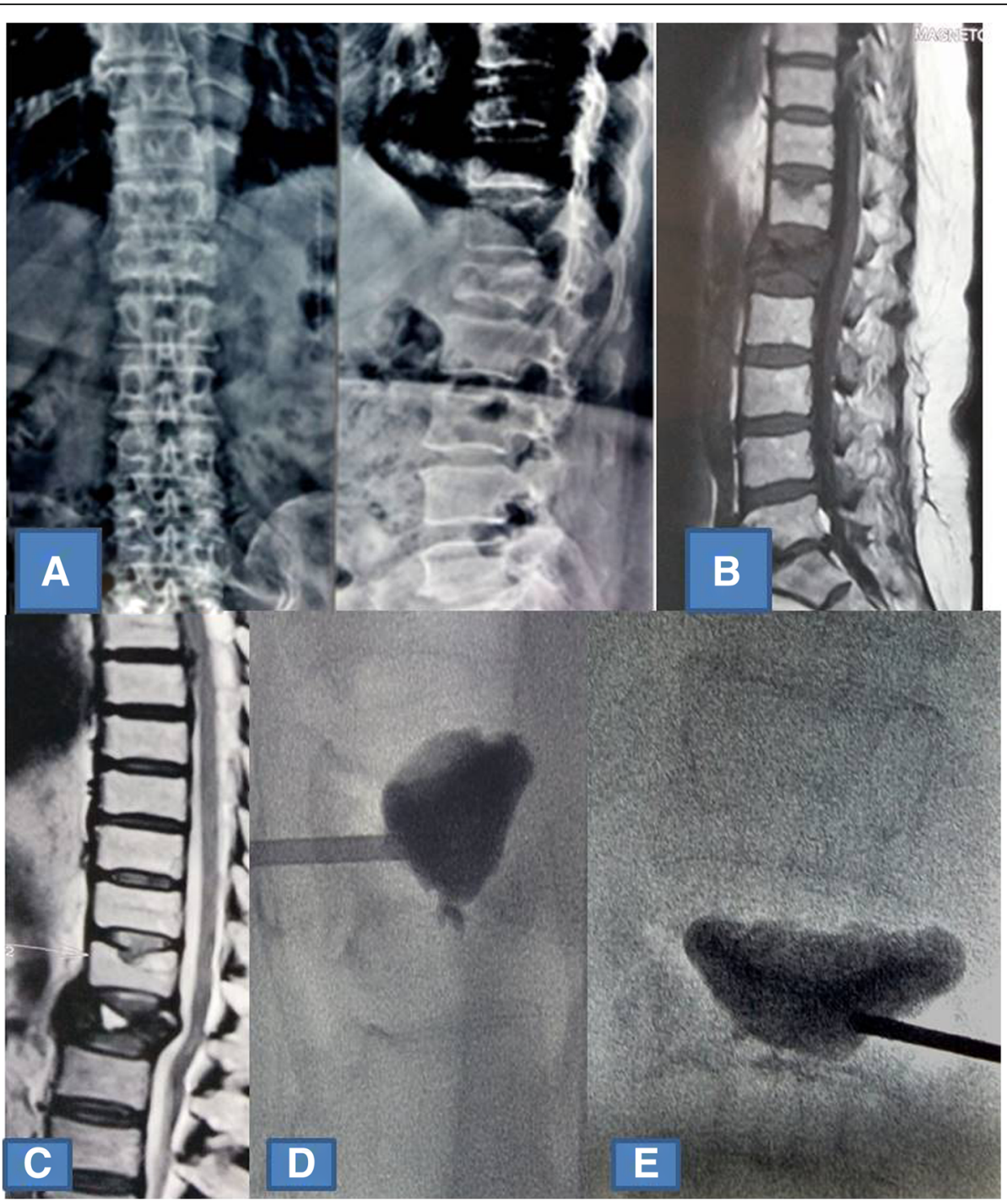

Fig. 7 A 65-year-old female with history of trauma 3 months back and had low back ache since then with difficulty in walking and tenderness at L1 and L2 vertebral level. She also had complaints of tingling and numbness in bilateral lower limb. a X-ray Thoracolumbar spine AP and lateral view showing post-traumatic collapse of L1 vertebra. b MRI T1 and c MRI T2WI showing collapse of L1 with adjacent bone edema and thecal sac compression. $\mathbf{d}$, e DSA fluoroscopic images AP and lateral view showing adequate filling of L1 vertebral body by cement. On the seventh day of follow-up visit, pain and tenderness was persistent with symptoms of radiculopathy. On 3-month follow-up, pain was persistent though

decreased in intensity with persistence of radiculopathy

The frequency of patient presenting with back pain of 1-6-month duration was maximum (20 patients, $40 \%)$ followed by $12-24$ months (24\%), 6-12 months (20\%), and $>24$ months $(16 \%)$.

Pre-procedure imaging findings showed bone edema to be the most prevalent followed by degenerative changes and anterior wedging of vertebral body (Fig. 8).

Mean preoperative pain score was $7.3 \pm 1.2$, and activity score was $1.6 \pm 1.1$. The medication (analgesic) score was $1.0 \pm 0.2$ (Table 1 ).

The most common route of vertebroplasty was right transpedicular (52\%) followed by left transpedicular (36\%) and bipedicular (12\%). Figure 4 showed bipedicular approach where injection was done one by one from each side as no appropriate distribution of cement was there when injected from one side.

The amount of cement injected through bipedicular route was more as compared to that of unipedicular route. There was no significant difference $(p=0.4$ which is insignificant; for significance, $p$ should be less than 0.05 ) between the amount of pain relief and the amount of cement injected irrespective of the unipedicular or bipedicular approach (Table 2). 
Preprocedure Imaging findings

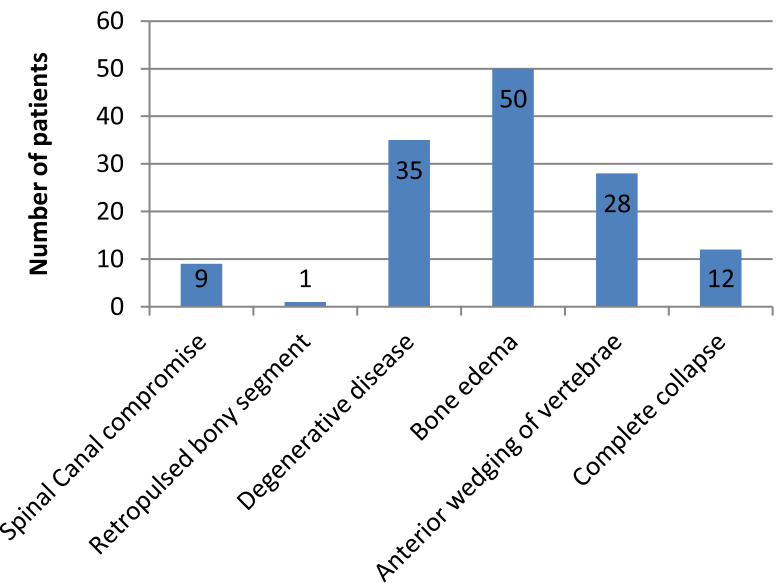

- Preprocedure Imaging findings

Fig. 8 Pre-procedure imaging findings

\section{Complications}

Intraprocedure pain

In 10 (20\%) procedures, patients complained of intraprocedural pain despite routine pre-medications. Injectable analgesia was given but two patients had persistent pain even after analgesia.

Two patients had extension of cement in paravertebral veins, and one had extension of cement in to pulmonary artery (Fig. 6 shows paravertebral extension as well as pulmonary embolism in one patient). However, both the patients were asymptomatic but required vital monitoring for few hours. To rest, all patients were sent home $2 \mathrm{~h}$ after the procedure. One of the patients had epidural extension of cement with increased severity of pain postprocedure which was relieved by analgesics (Table 3 ).

Ten patients (20\%) had local site swelling and tenderness post-procedure for which analgesics and antibiotics were given for 7 days. At the seventh followup day, pain and tenderness have significantly reduced in all. Two patients had complaints of paraesthesia and tingling numbness in lower limbs which got relieved by conservative means at 1 week follow-up.

Paired sample $t$ testing of preoperative versus postoperative pain score, activity score, and medication score were done at the seventh day and 3-month follow-up. It was found to be insignificant ( $p<0.05$ is taken as significant) at the seventh day. However, at 3 months, and it was found to be significant. This suggests that there is

Table 1 Pain score, activity score and medication score

\begin{tabular}{lll}
\hline Pre-vertebroplasty & & \\
\hline Index & Mean & Standard deviation \\
\hline Pain & 7.30 & 1.2 \\
Activity score & 1.6 & 1.1 \\
Medication score & 1 & 0.2 \\
\hline
\end{tabular}

significant relief in clinical symptoms that might take some time and is static thereafter (Tables 4 and 5).

It was found that patients with pain duration $<12$ month has significant reduction in pain score and activity score $(p<0.05)$ while patients with duration of pain $>12$ month had insignificant results suggesting that there was no significant reduction in the severity of pain score and activity score in patients with chronic/long duration pain (Table 6).

On applying paired $t$ test, there was a significant ( $p<$ $0.05)$ reduction in pain score and activity score on comparing the pre-vertebroplasty and post-vertebroplasty score irrespective of the type of vertebral pathology (Table 7).

We also compared patients in whom there was radiculopathy, and it was found that pain relief in them is not significant (Table 8).

On following these patients for two more years (till December 2017), there has been no change in pain relief or severity, which was there after 3 months of the procedure which concludes that pain that responds to vertebroplasty does so within 3 months and no further effect of pain relief is there, but no further increase in pain was noted even in patients where the results were static.

\section{Discussion}

Percutaneous vertebroplasty was first introduced in 1987 by Galimbert and Deramond, a French neurosurgeon and radiologist, respectively, as an "alternative" treatment for vertebral hemangiomas [3]. The technique consists of an injection of an acrylic material, poly methylmethacrylate (PMMA), in the pathological vertebral body. When the great potential of this procedure became evident, its indications were extended to vertebral collapses of osteoporotic or different etiologies and to primary and repetitive vertebral neoplasm. Today, it 
Table 2 Vertebral approach,size of needle used and amount of cement injected

\begin{tabular}{llllll}
\hline Approach & No. of procedures & $\begin{array}{l}\text { Size of needle } \\
\text { used }\end{array}$ & $\begin{array}{l}\text { Mean amount of } \\
\text { cement injected(in ml) }\end{array}$ & $\begin{array}{l}\text { Standard } \\
\text { deviation }\end{array}$ & $\begin{array}{l}\text { Amount of pain relief unipedicular versus bipedicular } \\
\text { and amount of cement injected }(p \text { value) }\end{array}$ \\
\hline Unipedicular & 44 & $13 \mathrm{G}$ & 5.3 & 1.5 & $P=0.4$ (Insignificant) \\
Bipedicular & 6 & $13 \mathrm{G}$ & 7.3 & 1.7 & \\
\hline
\end{tabular}

has become an essential technical tool with the interventional neuroradiologist for the treatment of vertebral painful syndromes.

In our study, $26 \%$ were male and $74 \%$ were female patients with mean age $52.65 \pm 13.1$ (range 20-69 years). All patients presented with moderate to severe backache. Local tenderness was the most common complaint and was noted in $20(40 \%)$ patients. Difficulty in walking was present in $10(20 \%)$ patients. Sensory deficit and bladder involvement was noted in $8(16 \%)$ and $3(6 \%)$ patients, respectively.

Out of the 50 patient's in our study, 11 patients $(22 \%)$ had vertebral hemangioma, 36 (72\%) had osteoporotic/ traumatic collapse, and $3(6 \%)$ of them had vertebral collapse due to malignant etiology (multiple myeloma).

On pre-procedure imaging, the vertebral body was involved in all of the cases, and the most common vertebrae was D12 in 11 patients (22\%) followed by L1 in 10 patients (20\%).

Route of vertebroplasty and correlation between amount of relief in pain on the basis of amount of cement injected and unipedicular versus bipedicular approach

Percutaneous vertebroplasty is usually done via bipedicular approach for better lesion filling. But unipedicular approach has several advantages. It is less time consuming, associated with less complication. However, it is slightly more difficult to use the unipedicular approach than the bipedicular in the thoracic spine, given the relatively small size of pedicles in the thoracic region [8].

Kim et al. described a modified unipedicular approach in which more lateral angulation of the needle was suggested. They compared the technique with a bipedicular approach. Lesions filling across the midline were achieved in $96 \%$ of cases with mean filling of $77 \%$ in both vertebral halves. There was no statistically significant difference in clinical outcome from that of bipedicular route. The author considers this lateral approach to be considerably safe with little risk of neural injury [8].

Table 3 Technical complications

\begin{tabular}{lll}
\hline Technical Complications & Number of patients & Percentage \\
\hline Paravertebral venous filling & 2 & $4 \%$ \\
Disc space filling & 9 & $18 \%$ \\
Epidural extension & 1 & $2 \%$ \\
Pulmonary embolism & 1 & $2 \%$ \\
\hline
\end{tabular}

We performed all the 50 procedures via transpedicular route and lateral approach. We did $6(12 \%)$ procedures via bipedicular approach and 44 procedures (88\%) via unipedicular approach. Bipedicular injection was used when satisfactory filling was not achieved after first injection. By our study, we found statistically significant difference in the amount of cement injected in unipedicular versus bipedicular procedures with more amount of cement injected in bipedicular approach.

The amount of pain relief from bipedicular approach as compared to unipedicular approach and also the amount of cement injected were found to be insignificant $(p=0.4)$ in relief of pain.

\section{Complications}

The major risk of vertebroplasty is related to the possibility of cement leak in the prevertebral and paravertebral venous plexus with risk of spinal cord compression or pulmonary embolism [9].The rate of thromboembolic complications has been reduced considerably by the increased operator skills and the use of denser cements, and it is now the complication rates are around $0.5-1 \%$ [10].

Many studies have found that cement leakage into the intervertebral disc space and paravertebral soft tissues were frequent and almost always asymptomatic $[5,11,12]$.

We also had nine patients (18\%) with extension of cement into the IV disc space but were asymptomatic with no long-term complications.

In one study, cement leakage into the disc was found in $5(25 \%)$ of 20 patients, with none of them having any complications [13]. Similarly, in other series, slight PMMA leak into the disc space, epidural fat, and paravertebral veins were observed in 20 (38\%) of 52 vertebroplasties; the leaks were symptomatic in only 5 vertebroplasties [14]. These authors suggest that slight PMMA leaks, when not symptomatic, should not be considered as complications; moreover, there is no direct

Table 4 Post procedural clinical pain relief

\begin{tabular}{llll}
\hline Clinical status & $\begin{array}{l}\text { Immediate Patient } \\
\text { (percentage) }\end{array}$ & $\begin{array}{l}\text { 7th day Patient } \\
\text { (percentage) }\end{array}$ & $\begin{array}{l}3 \text { months Patient } \\
\text { (percentage) }\end{array}$ \\
\hline Asymptomatic & $0(0 \%)$ & $3(6 \%)$ & $16(32 \%)$ \\
Improved & $8(16 \%)$ & $14(28 \%)$ & $30(60 \%)$ \\
Static & $42(84 \%)$ & $33(66 \%)$ & $4(8 \%)$ \\
Deteriorated & $0(0 \%)$ & $0(0 \%)$ & $0(0 \%)$ \\
\hline
\end{tabular}


Table 5 Pain score, activity score and medication score after 7 days and 3 months post procedure

\begin{tabular}{|c|c|c|c|c|c|c|c|c|}
\hline \multicolumn{3}{|l|}{ Prevertebroplasty } & \multicolumn{3}{|c|}{ Post vertebroplasty follow up after 7 days } & \multicolumn{3}{|c|}{ Post vertebroplasty follow up after 3 months } \\
\hline & Mean & Standard deviation (SD) & Mean & SD & $P$ value & Mean & SD & $P$ value \\
\hline Pain score & 7.3 & 1.2 & 5.7 & 1.1 & 0.06 & 2.4 & 1 & 0.004 \\
\hline Activity score & 1.6 & 1.1 & 1.2 & 0.4 & 0.11 & 0.6 & 0.09 & 0.003 \\
\hline Medication score & 1 & 0.2 & 0.7 & 0.1 & 0.15 & 0.3 & 0.06 & 0.004 \\
\hline
\end{tabular}

relationship between the rate of PMMA leakage and the severity of vertebral body compression.

In one study, it was recommended that placement of the needle in the central part of the vertebra decreases the risk of cement leakage thus preventing complications [15].

In another study, different factors were evaluated which can keep the low rate of cement leakage like usage of PMMA, which polymerizes rapidly, and can reduce extravasation. Liquid consistency of PMMA increases extravasation. Insufficient polymerization has been implicated as a major risk factor for pulmonary embolization, which, in some series, had been fatal [16].

The second important factor is the volume of cement injection. Few authors have correlated complications with excessive PMMA injection, whereas others found no correlation [17].

In our study, we do not found any correlation between the volume of cement injected and the incidence of complications but certainly liquid consistency of cement led to more leakage than less liquid cement injection; moreover, when there is leakage it is better to wait for some time before injecting again which leads to solidification and less further leakage.

Kyung et al. however stated more incidence of epidural leak when a larger volume of cement is injected in osteoporotic fractures [18]. A transient decrease in blood pressure is generally observed during the injection which has been attributed to vasodilatation which is supposed to be the consequence of methylmethacrylate toxicity [19].

In our study, technical complications were seen in $26 \%$ of cases, in the form of an extravasation of cement into the paravertebral venous plexus in two patients (4\%). Epidural leak and venous extension of contrast in to the IVC tributaries was seen in one patient each $(2 \%)$ and intervertebral disc space filling was observed in nine patients (18\%), while one patient had asymptomatic extension of cement mixture into the pulmonary artery branches.

Clinical complications was seen in $24 \%$ cases ( 2 major and 10 minor complications) out of which 2 patients (4\%) had major complications like paraaesthesias, tingling and numbness in the bilateral lower limb which were relieved in a 7-day follow-up without any intervention. Ten patients $(20 \%)$ had minor complications like local site swelling and tenderness for which analgesics and antibiotics were prescribed for 7 days after which the swelling and tenderness subsided.

\section{Pain relief and activity score after vertebroplasty in various pathologies}

As described in various case series and studies, pain relief is expected after a mean of $24 \mathrm{~h}$ after the procedure. Marked or complete pain relief was demonstrated in $90 \%$ of patients with osteoporotic compression fracture and hemangiomas and $70 \%$ of patients of vertebral metastasis and myeloma [13, 14]; however, we found no correlation between the type of vertebral pathology and the amount of relief of pain or activity ( $p$ value was insignificant $>0.05$ )

\section{Pain relief and activity score after vertebroplasty immediately, at the 7-day follow-up and at 3-month follow-up}

In the series of 24 patients, Boschi et al. found marked pain relief in 8 patients within $24 \mathrm{~h}$. In 10 patients, the pain disappeared 5-6 days after operation and in 6 patients after 2 weeks (thoracic spine localization). Following the postoperative period of the next 4-9 years, they did not record the pain recurrence. The average extent of pain severity decreased from 8.40 preoperatively to 0.851 month postoperatively $(p<0.001)$ [20].

Table 6 Correlation between duration of pain and amount of pain relief post procedure

\begin{tabular}{|c|c|c|c|c|c|c|c|c|c|c|}
\hline \multicolumn{4}{|l|}{ Pre-vertebroplasty } & \multicolumn{3}{|c|}{ Post vertebroplasty 7th day } & \multicolumn{4}{|c|}{ Post-vertebroplasty follow up after 3 month } \\
\hline $\begin{array}{l}\text { Duration of pain } \\
\text { (in months) }\end{array}$ & $\begin{array}{l}\text { Mean Pain } \\
\text { score }\end{array}$ & $\begin{array}{l}\text { Mean activity } \\
\text { score }\end{array}$ & SD & $\begin{array}{l}\text { Mean pain } \\
\text { score }\end{array}$ & $\begin{array}{l}\text { Mean activity } \\
\text { score }\end{array}$ & $P$ value & $\begin{array}{l}\text { Mean Pain } \\
\text { score }\end{array}$ & $\begin{array}{l}\text { Mean activity } \\
\text { score }\end{array}$ & SD & $P$ value \\
\hline 1-6 ( 20 patients) & 8.1 & 1.2 & 1.8 & 4.82 & 1.1 & 0.041 & 2.5 & 0.8 & 1.3 & 0.002 \\
\hline 6-12 (10 patients) & 7.2 & 1.1 & 1.7 & 4.9 & 1.1 & 0.09 & 2.2 & 0.9 & 1 & 0.004 \\
\hline 12-24 ( 12 patients) & 7.7 & 1.02 & 1.3 & 5.65 & 1.04 & 0.14 & 4.1 & 1.2 & $1 . .1$ & 0.43 \\
\hline >24 ( 8 patients) & 8 & 1.2 & 1.6 & 6.2 & 1.05 & 0.18 & 6.6 & 1.8 & 1 & 0.64 \\
\hline
\end{tabular}


Table 7 Vertebral pathology and amount of Pain relief

\begin{tabular}{|c|c|c|c|c|c|}
\hline \multicolumn{3}{|l|}{ Pre-vertebroplasty } & \multicolumn{3}{|c|}{ Post-vertebroplasty follow up after 3 month } \\
\hline $\begin{array}{l}\text { Pathology ( no of patients in bracket) } \\
\text { (a) }\end{array}$ & Mean Pain score & Mean activity score & Mean Pain score & Mean activity score & $P$ value \\
\hline Hemangioma (11) & 8.0 & 1.6 & 4.1 & 0.4 & 0.002 \\
\hline Osteoporotic (36) & 6.9 & 1.5 & 3.6 & 0.2 & 0.005 \\
\hline Metastatic/Neoplastic (3) & 6 & 1 & 3 & 0.5 & 0.002 \\
\hline
\end{tabular}

Cyteval et al. [13] found in their study that there was immediate (within $24 \mathrm{~h}$ ) pain relief in $75 \%$ of patients treated for painful osteoporotic collapse.

In our study, we compared pre- and post-procedure scores with paired $t$ test. Eight patients (16\%) had clinical improvement in symptoms on the day of the procedure. In the rest of the patients, there was no significant improvement.

On the seventh day of follow-up, three patients (6\%) had complete relief in pain and 14 patients $(28 \%)$ had mild relief in pain while 33 patients $(66 \%)$ had no improvement in amount of pain and activity as calculated by the scales. On statistical calculation, mean preoperative pain score was $7.3 \pm 1.2(\mathrm{SD})$, and their mean postoperative pain scores on the seventh day of follow-up was $5.7 \pm 1.1(\mathrm{SD})$ with a $p$ value of 0.06 which was statistically insignificant ( $p<0.05$ is considered as significant) suggesting that there was no significant relief in pain post-procedure on the seventh day of follow-up which was contrary to the above mentioned study which describes significant pain relief in maximum patients after 5-6 days. The $p$ value of mean activity score and medication score were 0.11 and 0.15 , respectively, which was insignificant suggesting no significant relief in activity and patient continued to take analgesics for pain relief (Table 9).

On the 3-month follow-up, 46 patients (92\%) had clinical relief in pain and activity while 4 (8\%) of them had no relief in symptoms. On statistical calculation, mean preoperative pain score was $7.3 \pm 1.2$ (SD), and their mean postoperative pain scores on the 3-month follow-up was $2.4 \pm 1$ (SD). The $p$ value of pain score, activity score, and medication score came out to be $0.004,0.003$, and 0.004 , respectively, which were statistically significant $(p<$ 0.05 considered to be significant) suggesting that there is significant relief in clinical symptoms at 3month follow-up.
There were no delayed complications of any sort seen in any of the patients in our study.

\section{Correlation of significance between effectiveness of vertebroplasty in patients based on duration of pain}

In our study, we studied correlation between the duration of pain patient had before the procedure and the amount of pain relief post-vertebroplasty. On seventh day and 3-month follow-up, we found that patients who had duration of pain less than 12 months had more relief in pain and significant increase in activity (signifying decreased morbidity) post-vertebroplasty ( $p$ value was $<0.05$, significant) as compared to patient who presented with long duration pain $>12$ months ( $p>0.05$, insignificant).

So, with the above findings, we came to a conclusion that with chronicity of pain, the effectiveness of vertebroplasty in reduction of pain and thus improving the quality of life decreases. Though no large studies have been done related to the effectiveness of vertebroplasty based on duration of pain to support our findings. We also observed that patients with complaints of associated radicular pain had insignificant relief in pain post-vertebroplasty ( $p$ value for mean pain score 0.5 , insignificant) as compared to patients with no radiculopathy $(p<0.001)$.

\section{Conclusion}

Based on our study, we conclude that vertebroplasty represents a safe, cost-effective, and a very beneficial therapeutical option available for the neuroradiologist and interventional radiologist for the treatment of pain associated with vertebral fractures/collapse associated with different vertebral pathologies with high success rate. With our study, we also came to a conclusion that the accurate and correct selection of the patients is mandatory. We concluded that there was no correlation with the amount of cement injected

Table 8 Comparison between patients with or without associated radiculopathy

\begin{tabular}{|c|c|c|c|c|c|}
\hline \multicolumn{3}{|l|}{ Pre vertebroplasty } & \multicolumn{3}{|c|}{ Post-vertebroplasty follow up after 3 months } \\
\hline Radiculopathy & Mean Pain score & Mean activity score & Mean Pain score & Mean activity score & $P$ value \\
\hline Present (6 patients) & 7.6 & 1.8 & 6.1 & 1.3 & 0.5 \\
\hline Absent (44patients) & 7.8 & 1.5 & 2.2 & 0.9 & 0.001 \\
\hline
\end{tabular}


Table 9 depicting Effect of percutaneous vertebroplasty on pain relief in various studies compared to our study

\begin{tabular}{llllll}
\hline Author & $\begin{array}{l}\text { Followup } \\
\text { (months) }\end{array}$ & $\begin{array}{l}\text { Mean pain score } \\
\text { pre vertebroplasty }\end{array}$ & $\begin{array}{l}\text { Mean pain score } \\
\text { post vertebroplasty }\end{array}$ & $\begin{array}{l}\text { Patients with pain } \\
\text { relief \% within 24 hour }\end{array}$ & $\begin{array}{l}\text { Patients with pain } \\
\text { relief \% long term }\end{array}$ \\
\hline Kyung 2002 [19] & 3 & - & - & 60 & 87 \\
Grados F 2000 [21] & 48 & 8 & 3.4 & - & 96 \\
Cyteval C 1999 [14] & 6 & $7.5-9.5$ & - & 75 & 100 \\
McGraw 2002 [22] & $6-44$ & 8.9 & 2.02 & 97 & 93 \\
Peh WC 2002 [23] & $3-24$ & 8.3 & - & - & 16 (partial) 84( static) \\
Our study & $3-36$ & 7.3 & 2.4 & & 32 (asymptomatic) \\
& & & & & 60 (improved) \\
8 (static)
\end{tabular}

and pain relief. We did not find any significant difference in the amount of pain relief in bipedicular approach as compared to that in unipedicular approach, and also, we found that pain with less duration are effectively alleviated than more chronic pain. In experts, hand vertebroplasty is associated with minimal complications and is very safe procedure.

\section{Abbreviations}

ACR: American College of Radiology; CT: Computed tomography; DSA: Digital subtraction angiography; MRI: Magnetic resonance imaging; PMMA: Polymethyl methacrylate; SD: Standard deviation; VAS: Visual analog scale

\section{Acknowledgements}

The authors thank the departments of neurosurgery, neurology, hematology and endocrinology for their constant support.

\section{Authors' contributions}

VS and RVP are responsible for the concepts and definition of the intellectual content. VS, AT, and RVP did the design and are the guarantor. AT and SNP did the literature search. VS, AT, RVP, and ZN did the data acquisition. VS, RVP, ZN, and SNP did the data analysis. SNP provided the statistical analysis. VS, AT, and ZN prepared the manuscript. VS and ZN edited the manuscript. VS and SNP reviewed the manuscript. All authors read and approved the final manuscript.

\section{Funding}

No funding source to declare

\section{Availability of data and materials}

This was a prospective study, and patients were followed up in an outpatient department and on telephonic conversation.

\section{Ethics approval and consent to participate}

This project was approved by the institutional ethical committee, and all patients gave written consent to participate in this study.

\section{Consent for publication}

The data acquired from the patients were taken during the study.

\section{Competing interests}

The authors declare that they have no competing interest.

\section{Author details}

${ }^{1}$ Neuroradiology, SGPGIMS, Lucknow, India. ${ }^{2}$ ILBS, New Delhi, India.
Received: 30 June 2019 Accepted: 22 July 2019

Published online: 07 September 2019

\section{References}

1. Papaioannou A, Watts NB, Kendler DL, Yuen CK, Adachi JD, Ferko N (2002) Diagnosis and management of vertebral fractures in elderly adults. Am J Med. 113:220-228

2. McConnell CT Jr, Wippold FJ, Ray CE Jr et al (2014) ACR appropriateness criteria management of vertebral compression fractures. J Am Coll Radiol. 11(8):757-763

3. Galimbert $P$, Deramond $H$, Rosat $P$ et al (1987) Preliminary note on the treatment of vertebral angioma by percutaneous acrylic vertebroplasty. Neurochirurgie 33:166-168

4. Jensen ME, Evans AJ, Mathis JM, Kallmes DF, Cloft HJ, Dion JE (1997) Percutaneous polymethylmethacrylate vertebroplasty in the treatment of osteoporotic vertebral body compression fractures: technical aspects. AJNR Am J Neuroradiol 18:1897-1904

5. Deramond H, Wright NT, Belkoff SM (1999) Temperature elevation caused by bone cement polymerization during vertebroplasty [Suppl]. Bone 25: S17-\$21

6. San Millan Ruiz D, Burkhardt K, Jean B, Muster M, Martin JB, Bouvier J et al (1999) Pathology findings with acrylic implants. Bone 25:85S-90S

7. Bhawna SR, Joseph S (2006) Role of vertebroplasty in non infective vertebral collapse- a review article. Indian J Radiol Imaging 16:637-642

8. Kim AK, Jensen ME, Dion JE, Schweickert PA, Kaufmann TJ, Kallmes DF (2002) Unilateral transpedicular vertebroplasty: initial expirence. Radiology 222:737-741

9. Yeom JS, Kim WJ, Choy WS et al (2003) Leakage of cement in percutaneous transpedicular vertebroplasty for painful osteoporotic compression fractures. J Bone Jt Surg Br 85:83-926. https://doi.org/10.1302/0301-620X.85B1.13026

10. Brunot S, Berge J, Barreau X, Ménégon P, Dousset V (2005) Long term clinical follow up of vertebral hemangiomas treated by percutaneous vertebroplasty. J Radiol 86:41-47. https://doi.org/10.1016/S0221-0363(05 $\lcm{813216}$

11. Schmidt R, Cakir B, Mattes T, Wegener M, Puhl W, Richter M (2005) Cement leakage during vertebroplasty: an underestimated problem? Eur Spine J 14(5):466-473. https://doi.org/10.1007/s00586-004-0839-5

12. Cotten A, Dewatre F, Cortet B et al (1996) Percutaneous vertebroplasty for osteolytic metastases and myeloma: effects of the percentage of lesion filling and the leakage of methyl methacrylate at clinical follow-up. Radiology 200:525-530

13. Cyteval C, Sarrabeore MP, Oux JO et al (1999) Acute osteoporotic vertebral collapse: open study on percutaneous injection of arrylic surgical cement in 20 patients. AJR Am J Roentgenol 173:1685-1690

14. Weill A, Chiras J, Simon JM et al (1996) Spinalmetastasis: indications for the results of percutaneous example of acrylic surgical cement. Radiology 199: 241-247

15. Deramond H, Depriester C, Galibert P, Le Gars D (1998) Percutaneous vertebroplasty with polymethylmethacrylate: technique, indications, and results. Radiol Clin North Am 36:533-546

16. Fourney DR, Schomer DF, Nader R (2003) Percutaneous vertebroplasty and kyphoplasty for painful vertebral fracture in cancer patients. JNS(spine I) 98 : $21-30$ 
17. Martin JB, Jean B, Sugui K et al (1999) Vertebroplasty: clinical experience and follow-up results. Bone 25:11S-15S

18. Kyung SR, Chun KP, Moon CK, Joon KK (2002) Dose-dependent epidural leakage of polymethylmethacrylate after percutaneous vertebroplasty in patients with osteoporotic vertebral compression fractures. J Neurosurg 96(1 SUPPL):56-61

19. Kaufmann TJ, Jensen ME, Ford G, Gill LL, Marx WF, Kallmes DF (2002) Cardiovascular effects of polymethylmethacrylate use in percutaneous vertebroplasty. AJNR Am J Neuroradiol 23:601-604

20. Boschi V, Pogoreli Z, Gulan G, Perko Z, Grandi L, Radoni V (2011) Management of cement vertebroplasty in the treatment of vertebral hemangioma. Scand J Surg 100:120-124

21. Grados F, Depriester C, Cayrolle G, Hardy N, Deramond H, Fardellone P (2000) Long-term observations of vertebral osteoporotic fractures treated by percutaneous vertebroplasty. Rheumatology (Oxford). 39(12):1410-1414

22. McGraw JK, Lippert JA, Minkus KD, Rami PM, Davis TM, Budzik RF (2002) Prospective evaluation of pain relief in 100 patients undergoing percutaneous vertebroplasty: results and follow-up. J Vasc Interv Radiol 13(9):883-886

23. Peh WC, Gilula LA, Peck DD (2002) Percutaneous vertebroplasty for severe osteoporotic vertebral body compression fractures. Radiology. 223(1):121 126

\section{Publisher's Note}

Springer Nature remains neutral with regard to jurisdictional claims in published maps and institutional affiliations.

\section{Submit your manuscript to a SpringerOpen ${ }^{\circ}$ journal and benefit from:}

- Convenient online submission

- Rigorous peer review

- Open access: articles freely available online

High visibility within the field

- Retaining the copyright to your article

Submit your next manuscript at $\boldsymbol{\nabla}$ springeropen.com 